\title{
Aktivitas Harian Elang Jawa (Nisaetus bartelsi) di Bumi Perkemahan Sukamantri Taman Nasional Gunung Halimun Salak
}

\section{(Daily Activities of Javan Hawk Eagle (Nisaetus bartelsi) in Bumi Perkemahan Sukamantri Mount Halimun Salak National Park)}

\author{
Muhammad Luthfi*, Dewi Elfidasari, Pairah \\ Program Studi Biologi (Bioteknologi), Fakultas Sains dan Teknologi (FST), \\ Universitas Al Azhar Indonesia \\ Jl. Sisingamangaraja, Kby. Baru, Jakarta, Indonesia. 12110 \\ *Email: muhammadluthfi135@gmail.com
}

(Article History: Received 09 Juli 2020; Revised 12 Agustus 2020; Accepted 21 Agustus 2020)

\begin{abstract}
ABSTRAK
Burung merupakan salah satu fauna yang memiliki keanekaragaman hayati yang cukup tinggi di Indonesia dengan jumlah 1598 jenis burung, di antaranya terdapat burung pemangsa. Elang jawa (Nisaetus bartelsi) yang merupakan burung endemik di Pulau Jawa. Taman Nasional Gunung Halimun Salak (TNGHS) merupakan habitat bagi elang Jawa, hal ini dikarenakan kondisinya yang masih cukup baik. Penelitian ini bertujuan untuk mempelajari dan menganalisis aktivitas harian elang Jawa serta faktor yang mempengaruhi aktivitas elang jawa di TNGHS. Metode yang digunakan yaitu survei dan pemantauan sarang, pengamatan aktivitas harian, pengumpulan dan analisis data. Berdasarkan hasil pengamatan Nisaetus bartelsi di TNGHS, diperoleh aktivitas harian elang jawa yang terlihat adalah bertengger dengan persentase sebesar 66\%, dan terbang $34 \%$ dengan frekuensi waktu tertinggi aktivitas pada pukul 10:00-14:00. Aktivitas harian elang jawa juga dipengaruhi oleh lingkungan seperti suhu dan curah hujan di lingkungannya.
\end{abstract}

Kata Kunci: aktivitas harian; Elang Jawa; TNGHS

\section{ABSTRACT}

Bird is one of the fauna that has a fairly high biodiversity in Indonesia with a total of 1598 species of birds, including birds of prey. One of the birds of prey found in Indonesia is the Javan Hawk Eagle (Nisaetus bartelsi) which is an endemic bird on the Java island. Mount Halimun Salak National Park (HSNP) is one of the National Parks which is a habitat for Javan Hawk eagles, this is because the conditions are still quite good. This observation aims to study and find out the daily activities of the Javanese eagle and the factors that influence the activity of the Javan Hawk Eagle in HSNP. The methods used are nest surveying and monitoring, observing daily activities, collecting and analyzing data. Based on observations by Nisaetus bartelsi in HSNP, it was found that the Javan Hawk eagle's daily activity was perched with a percentage of $66 \%$, and flew $34 \%$ with the highest frequency of activity at 10:00 to 14:00. The daily activities of Javan Hawk eagles are also influenced by the environment such as temperature and rainfall in their environment.

Keywords: daily activities; Javan Hawk eagle; HSNP

\section{PENDAHULUAN}

Elang merupakan salah satu burung pemangsa dan menempati posisi sebagai konsumen teratas dalam rantai makanan di suatu ekosistem. Keberadaan burung pemangsa (raptor) dalam suatu ekosistem merupakan hal penting, karena posisinya sebagai pemangsa puncak dalam piramida atau rantai makanan. Oleh sebab itu, apabila terdapat gangguan terhadap mereka, maka akan terganggu pula rantai dan jaring-jaring makanan dalam ekosistem tersebut, baik secara langsung maupun tidak langsung (Ridwan et al. 2014). Selain itu kepekaannya terhadap lingkungan menjadikan mereka sebagai indikator lingkungan yang sehat. Apabila kondisi lingkungan terganggu, besar kemungkinan burung pemangsa akan segera punah. Berdasarkan peran tersebut, burung 
pemangsa dikategorikan sebagai satwa dilindungi (Prawiradilaga et al. 2003).

Salah satu burung pemangsa yang terdapat di Indonesia yaitu elang jawa (Nisaetus bartelsi). Sesuai dengan namanya, elang jawa merupakan burung pemangsa endemik di Pulau Jawa. Layaknya burung pemangsa, elang jawa merupakan burung pemangsa yang menduduki konsumen teratas (top predator) dalam jaring-jaring makanan (Pribadi 2014). Elang ini mengontrol populasi hewan lain yang menjadi mangsanya di alam Namun, keberadaan Elang Jawa di alam saat ini berada dalam keadaan genting. Elang Jawa termasuk ke dalam status endangered sementara berdasarkan CITES tergolong Apendix I.

Beberapa tahun terakhir ini daerah sebaran elang jawa sudah banyak terfragmentasi, sehingga saat ini diperkirakan persebarannya dihutan pulau jawa terpisah menjadi tiga bagian yaitu barat, tengah dan timur (Van Balen et al. 1999). Peningkatan ancaman terpisahnya populasi satu dengan yang lain terjadi di sebelah Barat dan Timur Pulau Jawa. Selain itu, perdagangan liarnya pun semakin meningkat dengan tingkat ancaman yang sangat tinggi sehingga mengakibatkan populasi elang jawa cenderung semakin menurun.

Taman Nasional Gunung Halimun Salak (TNGHS) merupakan salah satu Taman Nasional yang ada di Indonesia. TNGHS merupakan salah satu habitat bagi elang Jawa, hal ini dikarenakan kondisinya yang masih cukup baik (Prawiradilaga 2003). Oleh sebab itu kegiatan monitoring dan penelitian terhadap elang jawa diperlukan sebagai upaya pelestarian dan perlindungan terhadap spesies elang jawa. Kegiatan monitoring dan penelitian tentang elang jawa dilakukan secara berkelanjutan oleh pihak TNGHS bekerja sama dengan stakeholders yang memiliki kepedulian terhadap kelangsungan hidup elang jawa. Tujuan pengamatan ini untuk mempelajari dan mengidentifikasi aktivitas harian elang jawa (Nisaetus bartelsi) serta faktor yang mempengaruhi aktivitas elang jawa di TNGHS. Selanjutnya manfaat yang diharapkan dari penelitian ini yaitu sebagai referensi data untuk penelitian yang berkaitan dengan perilaku harian elang jawa.

\section{METODE}

Pengamatan dilakukan di Bumi Perkemahan Sukamantri Taman Nasional Gunung Halimun Salak, Bogor, Jawa Barat dari Februari 2020 hingga Maret 2020 yang berlangsung selama 16 hari pengamatan dengan jumlah total durasi waktu pengamatan sebanyak 100 Jam, yang berlangsung dari pagi hingga sore hari. Objek yang diamati adalah Elang jawa (Nisaetus bartelsi). Pengamatan aktivitas harian elang jawa dilakukan pada dua titik lokasi pengamatan (Gambar 1) yaitu pada, TP1 dan TP2 pada kawasan Bumi Perkemahan Sukamantri dengan koordinat sebagai berikut TP1: $-6^{\circ} 40$ '34,3'S 106 45'8,9'"E dan TP2: $\quad-6^{\circ} 40^{\prime} 34,3$ 'S $106^{\circ} 45^{\prime} 8,9^{\prime \prime} \mathrm{E}$.

Pengamatan perilaku harian elang jawa dengan menggunakan metode focal animal sampling yaitu mengamati satu individu yang menjadi fokus pengamatan, mencatat secara rinci perilaku yang terjadi pada periode waktu yang ditentukan. Metode pengumpulan data pada pengamatan ini mengenai aktivitas harian elang jawa diperoleh dengan pengamatan langsung di lapangan dengan menggunakan metode $a d$ libitum (Altmann 1974). Metode Ad-libitum adalah mencatat seluruh aktivitas pada saat pengamatan dengan menggunakan batasan perubahan aktivitas.

Pengamatan dilakukan ketika objek mulai melakukan aktivitas hingga selesai melakukan aktivitas. Data yang diambil pada saat pengamatan yaitu data yang diperoleh dari hasil pengamatan aktivitas harian berupa aktivitas terbang dan bertengger. Pengamatan aktivitas dilakukan pada dua tempat pengamatan yaitu pada area perkemahan dan kawasan hutan pada bumi perkemahan sukamantri. Pencatatan aktivitas harian dikelompokkan berdasarkan 
kategori perilakunya yaitu, perilaku terbang dan bertengger dengan variabel turunan antara lain adalah menelisik, bersuara, melihat (mengawasi), soaring, dan lain-lain.

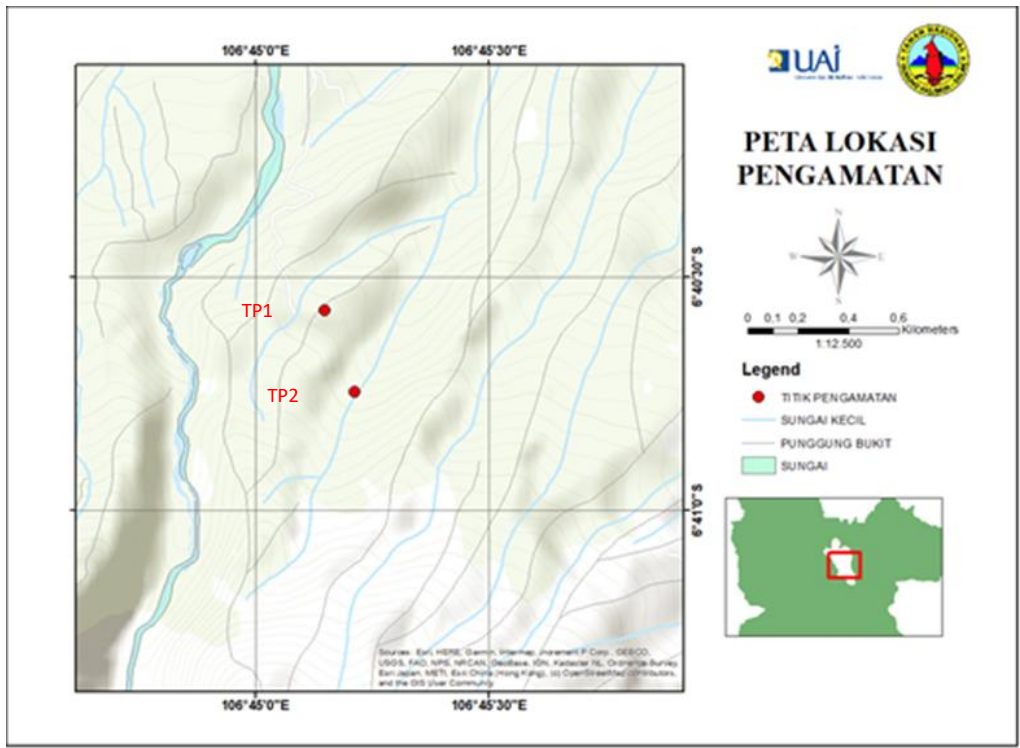

Gambar 1: Peta lokasi pengamatan aktivitas harian elang jawa (Nisaetus bartelsi)

Data lainnya yang diperoleh berupa data pengukuran suhu saat melakukan pengamatan aktivitas harian. Data kemudian dianalisis secara statistik. Setiap perilaku yang dicatat dengan metode ad-libitum dihitung presentasenya. Data perilaku yang didapat dari hasil pengamatan diolah menjadi proporsi kategori perilaku. Hasil dari perhitungan proporsi tersebut kemudian disajikan dalam bentuk diagram dan grafik aktivitas harian serta dijelaskan secara deskriptif. Rumus aktivitas elang jawa yang digunakan sebagai berikut:

$$
\text { Aktivitas }=\frac{\text { Jumlah Aktivitas }}{\varepsilon \text { Seluruh Aktivitas }} \times 100 \%
$$

\section{HASIL DAN PEMBAHASAN}

Aktivitas Harian Elang jawa (Nisaetus bartelsi)

Berdasarkan hasil pengamatan didapatkan bahwa elang jawa melakukan aktivitas dan perilaku harian secara berulang selama pengamatan, tergantung kondisi lingkungan sekitar. Hal ini disebabkan karena aktivitas dan perilaku harian elang jawa sangat tergantung pada kondisi lingkungan. Menurut Elfidasari (2001) perilaku merupakan tingkah laku alamiah makhluk hidup yang terkoordinasi dan tampak secara objektif, termasuk upaya penyesuaian diri terhadap perubahan lingkungan.

Hasil pengamatan didapatkan bahwa aktivitas harian elang jawa yang terlihat terbang dan bertengger dengan persentase bertengger $66 \%$, dan terbang 34\% (Gambar 2). Menurut Harianto et al (2015) bahwa waktu terbaik untuk menemukan dan mengidentifikasi elang jawa pada saat aktivitas elang mencari ketinggian dengan menggunakan perubahan suhu (aktivitas termal), yaitu pada pukul 09.00-10.00 WIB dengan cuaca cerah. Hasil ini disebabkan pada saat itu lingkungan sekitarnya dalam keadaan cerah, dan memiliki arus panas yang cukup bagi elang jawa untuk memulai aktivitasnya.

Pada saat pengamatan didapatkan aktivitas harian elang jawa tercatat aktif pada pukul 10:00 hingga 14:00 WIB, setelah itu aktivitas elang akan menurun pada sore hari (Gambar 3). Pada pukul 12.00-15.00 WIB aktivitas semua burung termasuk elang cendrung rendah, hal ini dipengaruhi oleh faktor lingkungan pada sore hari suhu akan menurun, sedangkan elang memanfaatkan suhu dan arus panas untuk melakukan aktivitasnya terutama pada saat terbang (Harianto et al. 2015) 


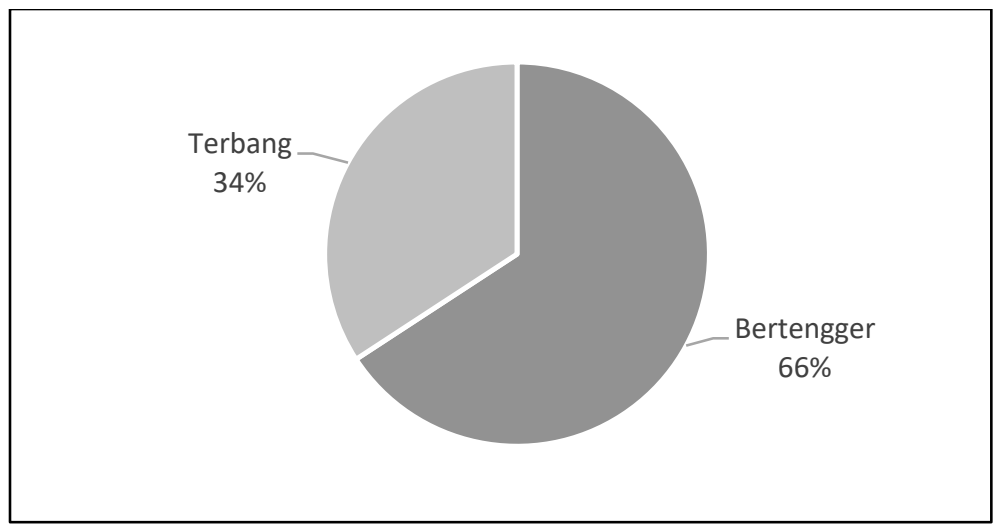

Gambar 2: Diagram aktivitas harian elang jawa (Nisaetus bartelsi)

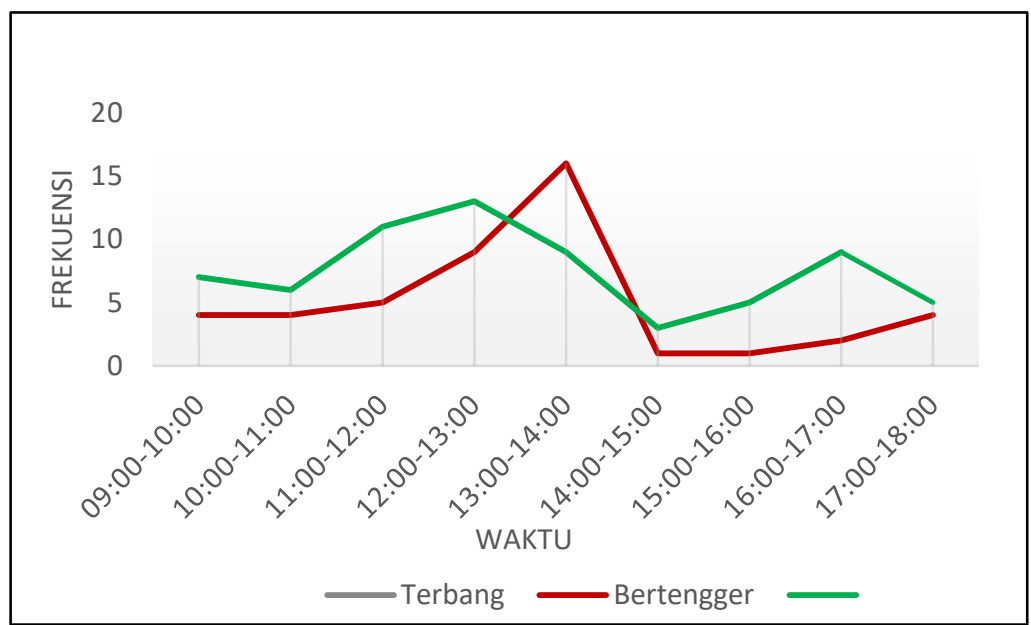

Gambar 3: Grafik aktivitas harian elang jawa (Nisaetus bartelsi)

Aktivitas harian dan perilaku pada individu elang jawa di kawasan hutan bumi perkemahan Sukamantri ini merupakan aktivitas yang terlihat dan dipengaruhi oleh cuaca seperti kabut tebal dan hujan. Akan tetapi, aktivitas elang jawa di bawah tajuk atau di dalam hutan tidak dapat teramati karena terhalangi oleh penutupan tajuk. Hal ini mengakibatkan aktivitas bertengger lebih sering terlihat dikarenakan faktor lingkungan yang terjadi di lapangan.

\section{Aktivitas Bertengger Elang Jawa}

Aktivitas elang jawa yang paling sering teramati yaitu bertengger. Aktivitas ini merupakan salah satu bentuk pengawasan terhadap kondisi sekitar. Pada aktivitas bertengger, terlihat perilaku mengawasi sekitar area tenggeran. Perilaku tersebut dilakukan dengan cara posisi tubuh berdiri tegak dan terlihat mengangkat satu kaki (lifting leg) sambil dimasukkan ke dalam bulu-bulu tubuh bagian ventral diikuti dengan melihat ke kiri dan ke kanan (Nasri 2014).

Aktivitas bertengger juga merupakan bentuk mekanisme mempertahankan suhu tubuh agar tetap stabil (termoregulasi) yang dilakukan agar proses fisiologis berjalan dengan optimal dan sebagai bentuk pengaturan laju metabolisme tubuh dan mengefisiensikan energi yang keluar untuk terbang. Aktivitas bertengger dimanfaatkan elang untuk merawat diri seperti menyelisik dan membersihkan badan sambil menggetarkan badan, aktivitas merapikan dan membersihkan bulu dada, sayap dan perut menggunakan paruh yang telah dilumuri minyak yang berasal dari kelenjar uropygial pada burung. Aktivitas ini 
berfungsi untuk menjaga bulu tetap bersih, mengkilat dan tahan terhadap air, karena bulu berfungsi melindungi tubuh dari hujan dan panas (Pasito 2014).

Aktivitas lainya yang dilakukan elang jawa saat bertengger yaitu bersuara. Perilaku ini berfungsi untuk pemberitahuan elang atas teritorinya dan juga berfungsi sebagai panggilan makan terhadap pasangan maupun anaknya serta pemberitahuan kemungkinan adanya ancaman. Aktivitas ini sering dilakukan saat elang sedang mengerami telurnya. Elang jawa mengeluarkan suara dengan tekanan suara sangat tinggi dan interval suara yang pendek, yaitu kwiek kwiiiek yang dilakukan sebelum melakukan aktivitas terbang (Prawiradilaga 2003). Makan dan mengawasi sekitarnya serta mengawasi buruannya pada pohon tenggeran termasuk aktivitas selingan yang rutin dilakukan elang saat bertengger. Aktivitas ini dilakukan pada pagi dan siang hari saat elang jawa baru memulai aktivitas pagi dan siang hari, perjumpaan terhadap aktivitas ini terjadi pada pukul 09:00 dan 13:00 pada saat pengamatan dilakukan.

Berdasarkan hasil pengamatan yang dilakukan terlihat bahwa aktivitas bertengger elang jawa merupakan perilaku yang paling banyak dilakukan yaitu, sebesar $66 \%$ dari total aktivitas harian yang berhasil dicatat. Hal ini sesuai dengan Afianto et al. (1999) yang menyatakan bahwa elang jawa menghabiskan $60 \%$ waktu hariannya untuk bertengger dan sisanya untuk terbang. Aktivitas bertengger elang jawa dapat dilakukan sepanjang hari sesuai kondisi lingkungan yang ada.

\section{Aktivitas Terbang Elang jawa}

Terbang adalah salah satu perilaku berpindah dari posisi yang lebih tinggi ke lebih rendah atau sebaliknya, maupun dari satu tenggeran ke tenggeran lain dengan disertai kepakan kedua sayap. Berdasarkan hasil pengamatan aktivitas terbang memiliki persentase aktivitas terbang sebesar 34\%. Aktivitas terbang sering terlihat dari pagi hingga siang hari pada pukul 10:00 hingga 14:00 WIB (Gambar 3). Aktivitas terbang meliputi, meluncur (gliding), terbang berputar (soaring), terbang naik turun (Undulating) dan berburu.

Perilaku terbang yang khas dari jenis burung pemangsa khususnya elang jawa yaitu soaring dan undulating. Perilaku soaring biasanya dilakukan untuk mengamati keberadaan mangsa di sekitarnya, mengajarkan anak terbang, menarik perhatian pasangan (pada musim berbiak), dan untuk menetapkan elang jawa saat terbang terlihat posisi rentangan sayapnya sedikit menyerupai huruf "V", dengan ekor cendrung dilancipkan. Hal ini ditujukan untuk efisiensi terbang. Saat elang jawa melakukan gliding posisi ekor lurus tidak mengembang sedangkan pada saat soaring posisi ekor mengembang dan saat elang jawa menukik posisi ekor dilancipkan dengan posisi sayap diarahkan ke belakang, hal ini dilakukan untuk menambah laju kecepatan turun dari elang tersebut (Widodo 2004).

Aktivitas lainnya yang muncul saat elang jawa terbang yaitu terbang membawa bahan untuk sarang dan terbang membawa mangsa, hal ini sering dijumpai pada saat elang jawa sedang breeding. Aktivitas terbang membawa bahan untuk sarang dilakukan agar menjaga kondisi sarang tetap hangat pada saat mengerami telurnya, sedangkan aktivitas terbang membawa mangsa yang didahului aktivitas berburu dilakukan untuk memberikan pakan terhadap pasangan yang sedang mengerami maupun untuk anakan yang masih juvenil satu

Berdasarkan pengamatan yang dilakukan, diketahui bahwa elang jawa paling banyak menghabiskan waktunya untuk bertengger, dibandingkan aktivitas terbang. Hal ini dapat disebabkan karena kemampuan terbang elang jawa yang terbatas bila kondisi hujan atau berkabut tebal, sedangkan pengamatan ini dilakukan selama musim hujan

\section{Pengaruh Lingkungan Terhadap Aktivitas Harian}

Burung memiliki kemampuan untuk memilih habitat yang sesuai dengan 
ketersediaan sumber daya yang mendukung kebutuhan hidupnya (Wiens 1992). Habitat utama elang jawa yaitu hutan pegunungan yang berada 500-2000 meter di atas permukaan laut dengan karakteristik hutan dengan kanopi tertutup dan kemiringan sedang yang memiliki aliran sungai. Habitat ini dimanfaatkan elang jawa untuk berburu dan bersarang. Menurut Cahyana (2015) peran kanopi hutan berkaitan langsung dengan ketersediaan pakan dan perilaku berburu, dikarenakan burung akan mencari habitat yang mampu menyediakan jenis pakan yang sesuai untuk memenuhi kebutuhan pakan (Watalee et al. 2013). Hal ini menyebabkan elang jawa lebih sering dijumpai melakukan aktivitas bertengger dan mengintai mangsanya dari balik kanopi hutan yang tersembunyi.

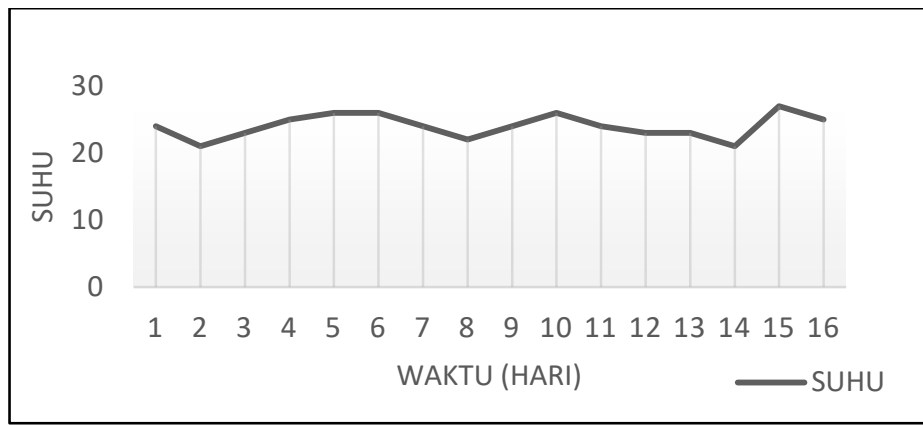

Gambar 4: Grafik suhu harian pada pengamatan aktivitas harian elang jawa

Berdasarkan pengukuran suhu pada pengamatan dan perhitungan jumlah curah hujan oleh Badan Klimatologi dan Geofisika (BMKG) dengan rata-rata suhu $24^{\circ} \mathrm{C}$ dengan curah hujan rata-rata 20,59 dan $31,1 \mathrm{~mm}$ pada bulan Februari-Maret 2020 (Gambar 4). Hal ini dapat berpengaruh terhadap kondisi lingkungan pada suatu wilayah dan vegetasinya (Adler \& Levin 2007). Hal ini dikarenakan curah hujan berpengaruh terhadap kondisi vegetasi di suatu wilayah (Van Steenis 2006).

Vegetasi yang beragam merupakan jaminan bagi keberadaan satwa mangsa yang menunjang keberlangsungan hidup elang jawa di TNGHS. Menurut Cahyana (2015), curah hujan yang tinggi dan temperatur suhu yang rendah juga mempengaruhi aktivitas harian elang jawa, hal ini berkaitan dengan perolehan data pada saat pengamatan, perjumpaan aktivitas bertengger memiliki persentase yang tinggi dibandingkan aktivitas terbang pada elang jawa dikarenakan elang memanfaatkan udara panas untuk melakukan aktivitas terbang seperti soaring (Widiana et al. 2017).

\section{KESIMPULAN}

Aktivitas harian elang jawa (Nisaetus bartelsi) yang memiliki persentase waktu paling besar yaitu aktivitas bertengger (66\%). Aktivitas ini meliputi perilaku menyelisik, bersuara, makan, membersihkan dan menggetarkan badan serta mengawasi buruan dan sekitarnya. Aktivitas terbang elang jawa memperoleh persentase sebesar $34 \%$ yang meliputi perilaku meluncur (gliding), terbang berputar (soaring), terbang naik-turun (undulating), berburu dan terbang membawa bahan untuk sarang. Berdasarkan hasil pengamatan, frekuensi perjumpaan terbesar pada aktivitas harian elang jawa terjadi pada pukul 10:00-14:00 WIB. Faktor lingkungan juga mempengaruhi aktivitas harian elang jawa seperti, suhu lingkungan dan curah hujan.

\section{DAFTAR PUSTAKA}

Adler PB, Levine JM (2007) Contrasting relationships between precipitation and species richness in space and time. Oikos 116(2): 221-232.

Afianto M, Hernomo J, Prawidilaga DM (1999) Aplikasi penggunaan radio telemetry pada pendugaan karakteristik 
wilayah jelajah elang jawa (Spizaetus bartelsi) di Gunung Salak. Yayasan Telapak Indonesia.

Altmann J (1974). Observational study of behavior: sampling methods. Behaviour 49: 227-266.

[BMKG] Badan Klimatologi dan Geofisika. Laporan iklim harian. http://dataonline.bmkg.go.id/akses_data [diakses pada tanggal 25-06-2020]

Cahyana AN (2015) Pemodelan spasial kesesuaian habitat elang jawa (Nisaetus bartelsi Stresemann, 1924) di Taman Nasional Gunung Halimun-Salak [Tesis]. Bogor(ID) . Sekolah Pascasarjana Institut Pertanian Bogor.

Elfidasari D (2001). Ekologi dan perilaku mencari makan tiga jenis kuntul di daerah sekitar Cagar Alam Pulau Dua Serang Provinsi Banten. [Tesis]. Bogor (ID). Program Pasca Sarja. Institut Pertanian Bogor

Harianto I, Andono A, Hasan M, Dewi YN, Tripraiawan T, Artawan IM, Suparman U, Syarifudin D (2015). Burung pemangsa [Raptor]. In Balai Besar Taman Nasional Gunung Gede Pangrango.

[IUCN] (2017) The IUCN Red List of Threatened Species. Version 2017-1 https://www.iucnredlist.org/species/226 96165/110050373 [diakses pada tanggal 06-01-2020]

Nasri GH, Yoza D (2014) Studi perkembangan perilaku elang jawa (Spizaetus bartelsi Stresemann 1924) di Pusat Rehabilitasi Suaka Elang Bogor. Fakultas Matematika dan Ilmu Pengetahuan Alam Universitas Riau

Prawiradilaga DM, Murate T, Muzakkir A, Inoue T, Kuswandono AA, Supriatna DE, Afianto MY, Hapsoro TO, Sakaguchi N (2003). Panduan survei lapangan dan pemantauan burungburung pemangsa. In BCP-JICA.

Pasito H, Prihatini W, Moerfiah (2014). Perilaku harian elang brontok (Nisaetus cirrhatus Gmelin, 1788) di Pusat Penyelamatan Satwa Cikananga Sukabumi. Fakultas Matematika dan
Ilmu Pengetahuan Alam Universitas

Pribadi DP (2014) Studi populasi elang jawa (Spizaetus bartelsi Stresemann, 1924) di Gunung Salak, Taman Nasional Gunung Halimun Salak. Bioma 10(1): 17-24.

Ridwan I, Rusli A (2014). Pemantauan ekologi sarang elang jawa (Spizaets bartelsi) di Wilayah Hutan Cikaniki Taman Nasional Gunung Halimun Salak. Jurnal Nusa Sylva 14(2): 43-46.

[TNGHS] Balai Taman Nasional Gunung Halimun Salak. 2013. https://halimunsalak.org/tentangkami/sejarah-kawasan/ [diakses pada 24-06-2020]

Van Balen S, Nijman V, Sözer R (1999). Distribution and conservation of the Javan Hawk-eagle Spizaetus bartelsi. Bird Conservation International 9(4): 333-349.

Van Steenis, CGGJ (2006) Mountain flora of Java, terjemahan A. Hamzah dan M. Toha. Pusat Penelitian Biologi-LIPI.

Watalee H, Ningsih S, Ramlah S (2013). Keanekaragaman jenis burung di hutan Rawa Saembawalati Desa Tomui karya Kecamatan Mori Atas Kabupaten Morowali. Warta Rimba 1(1): 1-8.

Widiana A, Iqba RM, Yuliawati A (2017) Estimasi luasan dan perkembangan daerah jelajah elang brontok (Nisaetus cirrhatus) pasca rehabilitasi di Pusat Konservasi Elang Kamojang Garut Jawa Barat. ISTEK X(2): 123-137.

Widodo T (2004) Populasi dan wilayah jelajah elang jawa (Spizaetus bartelsi Stresemann, 1924) di Gunung Kendeng Resort Cikaniki Taman Nasional Gunung Halimun. [Skripsi]. Bogor (ID). Fakultas Kehutanan. Institut Pertanian Bogor.

Wiens JA (1992) The ecology of bird communities, Volume 1: Foundations and Patterns. Cambridge University Press.

Wijaya KS (2008). Masalah infestasi ektoparasit pada beberapa jenis burung elang di habitat eks-situ. [Skripsi]. Bogor(Id). Fakultas Kedokteran Hewan. Institut Pertanian Bogor. 